\title{
Patterns of social relationships among community-dwelling older adults in Japan: latent class analysis
}

\author{
Kumi Watanabe Miura ${ }^{1,2}$, Takuya Sekiguchi ${ }^{2}$, Mihoko Otake-Matsuura ${ }^{2}$, Yuko Sawada ${ }^{3}$,Emiko Tanaka ${ }^{4}$, \\ Taeko Watanabe ${ }^{5}$, Etsuko Tomisaki ${ }^{6}$, Rika Okumura ${ }^{7}$, Yuriko Kawasaki ${ }^{7}$, Sumio Ito ${ }^{7}$ and Tokie Anme ${ }^{8^{*}}$
}

\begin{abstract}
Background: Social relationships may be the key to successful aging among older adults. However, little is known about the variability of social relationships among community-dwelling older people. This study aimed to describe the patterns of social relationships and examine the differences in sociodemographic characteristics and mental and physical health status among these patterns.
\end{abstract}

Methods: We obtained the data from a questionnaire survey in 2017 for older adults aged 65 and above who lived in a suburban area in Japan. The Index of Social Interaction (ISI) was used to evaluate social relationships. The final sample comprised 964 people who were independently mobile and answered at least one item of the ISI. To clarify the patterns of social relationships, latent class analysis was performed with five subscales of ISI treated as indicator variables. Multinomial logistic regression was conducted to examine the factors associated with the patterns of social relationships.

Results: The patterns of social relationships were classified into three classes: "Active" (73.6\%), "Socially isolated" (14.7\%), and "Less motivated" (11.7\%). Persons who had depressive symptoms were more likely to be allocated to the "Socially isolated" (Odds Ratio [OR] 1.80, 95\% Confidence Interval [CI] 1.13-2.86) or the "Less motivated" groups (OR 1.69, 95\% Cl 1.00-2.85) compared to the "Active" group. In addition, men (OR 1.72, 95\% Cl 1.07-2.76) and those living alone (OR 3.07, 95\% Cl 1.43-6.61) were more likely to be allocated to the "Socially isolated" group. Moreover, those who were dependent, according to the instrumental activities and daily living functions, were more likely to be assigned to the "Socially isolated" (OR 2.19, 95\% Cl 1.21-3.97) or "Less motivated" (OR 6.29, 95\% Cl 3.47-11.39) groups.

Conclusion: This study revealed the patterns of social relationships in older adults and suggested that there may be variations of social relationships among community dwellers. The results also indicated the necessity of assessing individual patterns of social relationships and devising strategies for each pattern in public health practice.

Keywords: Social relationships, Social isolation, Social support, Older adults, Aging

*Correspondence: tokieanme@gmail.com

${ }^{8}$ Faculty of Medicine, University of Tsukuba, 1-1-1 Tennodai, Tsukuba, Ibaraki 305-8575, Japan

Full list of author information is available at the end of the article

\section{Introduction}

Social relationships are the key to successful aging in old age. Connecting with friends, family, and society may give life meaning [1], contribute to happiness [2], satisfaction with life [3], and enhance an individual's emotional wellbeing [4]. In addition to contributing to emotional wellbeing, social relationships have been described in several

(c) The Author(s) 2022. Open Access This article is licensed under a Creative Commons Attribution 4.0 International License, which permits use, sharing, adaptation, distribution and reproduction in any medium or format, as long as you give appropriate credit to the original author(s) and the source, provide a link to the Creative Commons licence, and indicate if changes were made. The images or other third party material in this article are included in the article's Creative Commons licence, unless indicated otherwise in a credit line to the material. If material is not included in the article's Creative Commons licence and your intended use is not permitted by statutory regulation or exceeds the permitted use, you will need to obtain permission directly from the copyright holder. To view a copy of this licence, visit http://creativecommons.org/licenses/by/4.0/. The Creative Commons Public Domain Dedication waiver (http://creativeco mmons.org/publicdomain/zero/1.0/) applies to the data made available in this article, unless otherwise stated in a credit line to the data. 
studies as being related to mental and physical health outcomes using various definitions and terms. For example, many studies found that the association between social relationships and mental health outcomes has led to the onset of depression [5-7], while another study reported that being a member of social groups protects individuals against the onset of depression, alleviates symptoms of depression, and prevents depression relapse [8]. In terms of physical health, there may be an association between poor social relationships and all-cause mortality [9-11], cancer mortality $[12,13]$, and declining physical function $[14,15]$. Further, poor social relationships were also associated with cognitive health, such as the onset of dementia $[16,17]$. A review by Cohen [18] suggested that social relationships may affect an individual's health through the mechanism of stress buffering and health behavior modification. Hence, maintaining social relationships has great significance for the maintenance of good health and well-being in public health practices among older people.

Based on evidence from empirical studies, social relationship interventions have been conducted in several studies $[19,20]$. Previous studies in Japan reported that interventions based on community activity promotion might decrease the risk of long-term care [21] and declining cognitive functioning [22] among communitydwelling older adults. As awareness of the importance of social relationships increases, accumulating empirical knowledge for enhancing social relationships is critical in public health practices. Further, interventions tailored to target pre-identified barriers and characteristics are likely to improve professional practice [23]. Understanding the profiles of social relationships is expected to be significantly effective even in social relationships interventions.

Recently, several studies have reported attempts to classify social participation patterns. For example, a study in Switzerland identified four unique social participation patterns of older adults based on the type of activities that individuals engage in: "relatively inactive," "relatively active" (informal activities), "relatively active" (formal activities), and "highly active" [24]. Similarly, Ukawa et al. [25] identified activity types such as "sports groups/ clubs and hobby groups," and "political groups/organizations and industry/trade associations" as social participation patterns, and also found that the risk of long-term care outcomes differed by patterns among the Japanese older adult population. These studies indicate the possibility of variability of individual social patterns. People are exposed to various social environments in their daily lives, and understanding the diverse patterns of social relationships and the factors associated with them among older adults in the community can have important consequences for establishing basic knowledge for health practices. However, there is still a paucity of studies on social relationship patterns of older adults focusing on multiple aspects of social relationships as previous studies have focused on specific elements. Further, it is unclear how demographic factors are associated with these patterns.

Therefore, this study aims to 1) identify the patterns of various aspects of social relationships in daily life using latent class analysis (LCA) and 2) examine the differences in the patterns according to people's socio-demographic characteristics and mental and physical health status. Our approach that defines social relationships by multiple aspects rather than a specific element may describe the diversity of social relationships and reveal the subtypes of low social relationships, which have previously been recognized as a single group. Understanding the diverse patterns and its associated factors may provide insights for the development of public health interventions and strategies.

\section{Materials and methods \\ Study design and the participants}

This study employed a cross sectional study design and used data from the "Community empowerment and care for well-being and healthy longevity study (CEC study)." The study involves a questionnaire survey conducted every 2-3years for all the residents living in a suburban area (total population $=4539$ ) in central Japan, and investigates the factors related to well-being and longevity. The questionnaires were distributed using "the dropoff/pick-up" method. Accordingly, municipality-assigned volunteers visited all residents living in the study setting and distributed the questionnaires. After 2 weeks, volunteers revisited the participants to collect the completed questionnaires. We used the data from the 2017 wave (April 2017) for this study. The two inclusion criteria for participants of this study were older adults aged over 65 years who were independent and mobile. Of a total of 1085 participants, who responded to the 2017 wave survey (response rate: $85.1 \%$ ), 964 participants who met inclusion criteria and answered at least one item of the ISI were included in the final sample.

\section{Social relationships}

The Index of Social Interaction (ISI), which was developed to measure various aspects of social relationships in daily settings, showed high validity and reliability (Cronbach alpha 0.78) among Japanese community-dwelling older adults [26], and was therefore used in this study to provide the indicator variables. The ISI consists of 18 items and five subscales, each rated on a 4- or 5-point scale: 1) "independence," which measures social control involving feelings of obligation or responsibility toward a healthier lifestyle; 2) "social curiosity," which evaluates intellectual activities such as reading (e.g., newspapers, 
books, or magazines), trying to use new equipment, and having a hobby; 3) "interaction," which includes social networking such as family communication, non-family communication, and interactions with non-family persons; 4) "participation," which measures social participation such as participation in social groups, neighborhood-activities, and taking an active role in society; and 5) "feeling safe," which evaluates social support from the receipt of counseling and having someone to provide support in an emergency. One point was given for each item with a positive response, and zero points were given for a negative response, and each subscale score was calculated by summing up the item scores. The distribution exhibited high skewness (Supplement 1), and accordingly, the ISI subscale scores were dichotomized into the "high (> perfect score)" and "low (< perfect score)" groups to conduct the LCA analysis.

\section{Covariates}

Age, sex, family structure, subjective economic status, the instrumental activities and daily living (IADL) functions, disease status, and depressive symptoms were introduced as covariates. Information on the covariates was obtained from the questionnaires.

While age was treated as a continuous variable, family structure was categorized as living alone or other. Subjective economic status was obtained by asking one question: How severe do you feel your current living economic situation is? Participants who answered, "Very severe" and "Severe" were defined as the "poor" group, and other answers such as "Average" and "Good" were defined as the "better-off" group. The IADL variable was used with the subscale of IADL in the Tokyo Metropolitan Institute of Gerontology Index of Competence [27]. The items had three options for each question according to the guidelines of the Ministry of Health, Labour and Welfare in Japan [28]. The IADL scores ranged from 0 to 5 in which a score of 5 was defined as independent and any score between 0 and 4 was defined as dependent. The disease status (heart disease, diabetes, and musculoskeletal disorder) of the participants was defined based on their answers. Depressive symptoms were screened and assessed through two questions that asked about depressed moods [29]. If a participant answered "yes" to at least one question, they were defined as having depressive symptoms.

\section{Statistical analysis}

In this study, we determined (1) the pattern of social relationships and (2) the association between demographic factors and the patterns of social relationships.

First, LCA was conducted to determine the patterns of social relationships. LCA is a method that can be useful for clustering subgroups of latent classes [30]. In this study, five subscales of social relationships in the ISI were used as observed indicators in the LCA. The number of latent classes was comprehensively determined by comparing robust indicators including the Bayesian Information Criterion (BIC), the adjusted Bayesian Information Criterion (aBIC), the Akaike Information Criterion (AIC) and the consistent Akaike Information Criterion (CAIC) among each of the models. Entropy was used to assess the accuracy of clustering. We used the full information maximum likelihood estimation to deal with missing values in the ISI scale. Participants with data missing in all the items of ISI were removed.

Second, participants were assigned to their most likely latent class after the best fit model was selected. A multinomial logistic regression model was subsequently computed to examine the association between the characteristics and the social relationship subtypes obtained. To deal with missing data in the multinomial logistic regression model, we used multiple imputation by the fully conditional specification method for covariates. We created 50 imputed data sets and integrated each result of the analysis. The level of significance was set at 0.05 . All statistical tests were performed using the SAS 9.4 version.

\section{Results \\ Model fitting}

Table 1 shows the model fit indicators of the LCA. We adopted the three-class model based on the lowest AIC (54.22), BIC (137.03), and aBIC (83.04), and interpretability. The three-class model showed a high entropy value (0.70), which justified conducting the regression analysis after assigning participants to their most likely latent class.

Supplementary Tables 1 and 2 present the descriptive statistics and correlation matrix for ISI scores. Subsequently, the independence and social curiosity subscales of ISI reported medium correlation.

Table 1 Model comparison of latent class analysis fit in social relationship patterns

\begin{tabular}{llllll}
\hline No. classes & AIC & BIC & CAIC & aBIC & Entropy \\
\hline 1 & 337.65 & 362.01 & 367.01 & 346.13 & 1.00 \\
2 & 84.65 & 138.23 & 149.23 & 103.29 & 0.66 \\
3 & 54.22 & 137.03 & 154.03 & 83.04 & 0.70 \\
4 & 57.22 & 169.26 & 192.26 & 96.21 & 0.60 \\
5 & 63.6 & 204.87 & 233.87 & 112.76 & 0.68 \\
\hline
\end{tabular}

Note: AIC Akaike Information Criterion, BIC Bayesian Information Criterion, CAIC Consistent Akaike Information Criterion, aBIC Adjusted Bayesian Information Criterion 


\section{Patterns of social relationships}

The conditional probabilities for each class are listed in Table 2. The three classes were identified as "Active" (73.6\%), "Socially isolated" (14.7\%), and "Less motivated" (11.7\%). Supplementary Table 3 presents the number of missing data among the three latent classes; $65.7 \%$ of participants have no missing data and $23.5 \%$ have missing data on only 1 ISI subscale. This means that $89.2 \%$ of participants have missing data on $0-1$ ISI subscales. Furthermore, only $0.6 \%$ of the participants have missing data in four subscales, which suggests that there were few cases where participants with few responses were inaccurately assigned to classes due to a lack of information.

The first class consisted of people with the comparatively highest conditional probabilities for all subscales that reflect highly social relationships. They were likely to engage in all aspects of social activities in their daily lives. This class was labeled as the "Active" class. The second class had the lowest conditional probability for interaction with others, social participation, and the feeling of safety. This class was labeled as the "Socially isolated" class. The subjects in the third class showed relatively lower conditional probability of independence and social curiosity. This class was labeled as "Less motivated."

\section{The association between demographic characteristics and class membership of social relationships}

Table 3 shows demographic characteristics and ISI indicators within the three latent classes of social relationships. The mean age for "Active," "Socially isolated," and "Less motivated" groups was $73.8( \pm 6.85), 73.6( \pm$ $7.59)$, and $78.3( \pm 8.26)$, respectively. Moreover, males accounted for 43.1, 55.1, and 42.9\% of the "Active," "Socially isolated," and "Less motivated" group, respectively. For ISI subscales, the "Less motivated" group reported relatively smaller means on the independence $(2.50 \pm 0.74)$ and social curiosity subscales $(3.58 \pm 0.67)$ than the "Active" and "Socially isolated" groups. Additionally, the "Socially isolated" group reported smaller means on the interaction $(2.10 \pm 0.74)$ and participation subscales $(2.69 \pm 0.73)$ than the "Active" and "Socially isolated" groups.

Table 4 shows the results of the crude and adjusted multinomial logistic regression models to examine the differences in demographic characteristics among social relationship patterns by showing which factors were associated with the higher likelihood of belonging to either the "Socially isolated" or the "Less motivated" group than to the reference category, the "Active" group. Persons who had depressive symptoms were more likely to be allocated to the "Socially isolated" or "Less motivated" groups ("Socially isolated": Odds Ratio [OR] 1.80, 95\% Confidence Interval [CI] 1.13-2.86; "Less motivated": OR 1.69, 95\% CI 1.00-2.85) after being controlled by covariates. Males (OR 1.72, 95\% CI 1.07-2.76) and those living alone (OR 3.07, 95\% CI 1.43-6.61) were more likely to be allocated to the "Socially isolated" group. In addition, those who were dependent according to the IADL function were more likely to be assigned to the "Less motivated" and "Socially isolated" groups ("Socially isolated": OR 2.19, 95\% CI 1.21-3.97; "Less motivated": OR 6.29, 95\% CI 3.47-11.39). Similarly, we developed models using the "Less motivated" group as the reference category to examine the differences in the demographic characteristics of the "Socially isolated" and "Less motivated" groups (See Supplementary Table 4). Those who were younger (OR $0.95,95 \%$ CI $0.91-0.99$ ), males (OR 2.01, 95\% CI 1.05-3.83), and independent in IADL (OR $0.35,95 \%$ CI $0.16-0.76$ ) were more likely to be allocated to the "Socially isolated" group.

\section{Discussion}

Despite the importance of social relationships for older people, the variability of social relationships has not been well understood; in addition, limited literature is available focusing on specific aspects of social relationships such as social participation activities. Thus, this study extracted the latent patterns across multiple aspects of social relationships among Japanese community-dwelling older adults.

We extracted three social relationships patterns: "Active," "Socially isolated," and "Less motivated" groups. This study not only showed that there are variations of social relationships among community dwellers, which is consistent with previous studies that described social activities patterns [24, 25, 31, 32], but also found that inactive social relationships can be classified into two subtypes, which were previously seen as one.

Table 2 Conditional item response probability of social relationships

\begin{tabular}{llllll}
\hline & Independence & Social curiosity & $\begin{array}{l}\text { Interaction with } \\
\text { others }\end{array}$ & Social participation & Feeling safe \\
\hline Class 1: Active (73.6\%) & 0.998 & 0.788 & 0.972 & 0.689 & 0.989 \\
Class 2: Socially Isolated (14.7\%) & 0.998 & 0.696 & 0.555 & 0.151 & 0.680 \\
Class 3: Less motivated (11.7\%) & 0.256 & 0.092 & 0.664 & 0.221 & 0.706 \\
\hline
\end{tabular}


Table 3 Demographic factors within three latent classes of social relationships

\begin{tabular}{|c|c|c|c|c|c|c|}
\hline & \multicolumn{2}{|c|}{ Active } & \multicolumn{2}{|c|}{ Socially Isolated } & \multicolumn{2}{|c|}{ Less motivated } \\
\hline & $\mathbf{n}$ & $\%$ & $\mathbf{n}$ & $\%$ & $\mathrm{n}$ & $\%$ \\
\hline \multicolumn{7}{|l|}{ Age } \\
\hline Mean $( \pm S D)$ & 73.8 & $( \pm 6.85)$ & 73.6 & $( \pm 7.59)$ & 78.3 & $( \pm 8.26)$ \\
\hline Missing & 0 & & 0 & & 0 & \\
\hline \multicolumn{7}{|l|}{ Sex } \\
\hline Male & 337 & $43.1 \%$ & 54 & $55.1 \%$ & 36 & $42.9 \%$ \\
\hline Female & 395 & $50.5 \%$ & 36 & $36.7 \%$ & 45 & $53.6 \%$ \\
\hline Missing & 50 & $6.4 \%$ & 8 & $8.2 \%$ & 3 & $3.6 \%$ \\
\hline \multicolumn{7}{|l|}{ Subjective economic status } \\
\hline Better-off & 578 & $73.9 \%$ & 66 & $67.3 \%$ & 57 & $67.9 \%$ \\
\hline Poor & 144 & $18.4 \%$ & 23 & $23.5 \%$ & 22 & $26.2 \%$ \\
\hline Missing & 60 & $7.7 \%$ & 9 & $9.2 \%$ & 5 & $6.0 \%$ \\
\hline \multicolumn{7}{|l|}{ Chronic disease } \\
\hline Heart disease & 52 & $6.6 \%$ & 8 & $8.2 \%$ & 7 & $8.3 \%$ \\
\hline Diabetes & 114 & $14.6 \%$ & 13 & $13.3 \%$ & 16 & $19.0 \%$ \\
\hline Musculoskeletal disorder & 72 & $9.2 \%$ & 9 & $9.2 \%$ & 8 & $9.5 \%$ \\
\hline Missing & 0 & $0.0 \%$ & 0 & $0.0 \%$ & 0 & $0.0 \%$ \\
\hline \multicolumn{7}{|l|}{ IADL } \\
\hline Independent & 621 & $79.4 \%$ & 69 & $70.4 \%$ & 31 & $36.9 \%$ \\
\hline Dependent & 98 & $12.5 \%$ & 21 & $21.4 \%$ & 45 & $53.6 \%$ \\
\hline Missing & 63 & $8.1 \%$ & 8 & $8.2 \%$ & 8 & $9.5 \%$ \\
\hline \multicolumn{7}{|l|}{ Depressive symptoms } \\
\hline Having & 208 & $26.6 \%$ & 40 & $40.8 \%$ & 33 & $39.3 \%$ \\
\hline Not having & 514 & $65.7 \%$ & 46 & $46.9 \%$ & 33 & $39.3 \%$ \\
\hline Missing & 60 & $7.7 \%$ & 12 & $12.2 \%$ & 18 & $21.4 \%$ \\
\hline \multicolumn{7}{|l|}{ Family structure } \\
\hline Living with someone & 663 & $84.8 \%$ & 78 & $79.6 \%$ & 67 & $79.8 \%$ \\
\hline Living alone & 33 & $4.2 \%$ & 11 & $11.2 \%$ & 3 & $3.6 \%$ \\
\hline Missing & 86 & $11.0 \%$ & 9 & $9.2 \%$ & 14 & $16.7 \%$ \\
\hline \multicolumn{7}{|l|}{ ISI Independence } \\
\hline Mean $( \pm S D)$ & 4.00 & $( \pm 0.00)$ & 4.00 & $( \pm 0.00)$ & 2.50 & $( \pm 0.74)$ \\
\hline Missing & 38 & & 3 & & 2 & \\
\hline \multicolumn{7}{|l|}{ Social curiosity } \\
\hline Mean $( \pm S D)$ & 4.74 & $( \pm 0.50)$ & 4.59 & $( \pm 0.61)$ & 3.58 & $( \pm 0.67)$ \\
\hline Missing & 174 & & 20 & & 13 & \\
\hline \multicolumn{7}{|l|}{ Interaction with others } \\
\hline Mean $( \pm S D)$ & 2.97 & $( \pm 0.19)$ & 2.10 & $( \pm 0.72)$ & 2.52 & $( \pm 0.75)$ \\
\hline Missing & 56 & & 2 & & 7 & \\
\hline \multicolumn{7}{|l|}{ Participation } \\
\hline Mean $( \pm S D)$ & 3.60 & $( \pm 0.61)$ & 2.69 & $( \pm 0.73)$ & 2.77 & $( \pm 0.96)$ \\
\hline Missing & 103 & & 15 & & 20 & \\
\hline \multicolumn{7}{|l|}{ Feeling safe } \\
\hline Mean $( \pm S D)$ & 1.99 & $( \pm 0.14)$ & 1.23 & $( \pm 0.81)$ & 1.53 & $( \pm 0.75)$ \\
\hline Missing & 15 & & 1 & & 1 & \\
\hline
\end{tabular}

Note: IADL Instrumental Activities of Daily living, SD Standard Deviation 
Table 4 Multinomial logistic regression analysis for class memberships of social relationships

\begin{tabular}{|c|c|c|c|c|}
\hline Class 2: Socially Isolated (ref = Class 1: Active) & Crude Odds & $95 \% \mathrm{Cl}$ & Adjusted Odds & $95 \% \mathrm{Cl}$ \\
\hline Age (Continuous) & $1.08^{* * *}$ & $1.05-1.11$ & 0.98 & $0.95-1.01$ \\
\hline Sex $=$ Male (ref. female) & $1.69^{*}$ & $1.08-2.65$ & $1.72^{*}$ & $1.07-2.76$ \\
\hline Subjective economic status $=$ Poor (ref. Better-off) & 1.38 & 0.832 .29 & 1.11 & $0.65-1.88$ \\
\hline \multicolumn{5}{|l|}{ Chronic disease $=$ Having (ref. Not having) } \\
\hline Heart disease & 1.25 & $0.57-2.71$ & 1.05 & $0.47-2.37$ \\
\hline Diabetes & 0.90 & $0.48-1.66$ & 0.82 & $0.44-1.55$ \\
\hline Musculoskeletal disorder & 1.00 & $0.48-2.06$ & 0.99 & $0.46-2.15$ \\
\hline IADL = Dependent (ref. Independent) & $1.91^{*}$ & $1.14-3.22$ & $2.19^{* *}$ & $1.21-3.97$ \\
\hline Depressive symptoms = Having (ref. Not having) & $1.99^{* *}$ & $1.28-3.11$ & $1.80^{*}$ & $1.13-2.86$ \\
\hline Living status = Living alone (ref = Living with someone) & $2.59^{* *}$ & $1.27-5.31$ & $3.07^{* *}$ & $1.43-6.61$ \\
\hline Class 3: Less motivated (ref $=$ Class 1: Active) & Crude Odds & $95 \% \mathrm{Cl}$ & Adjusted Odds & $95 \% \mathrm{Cl}$ \\
\hline Age (Continuous) & 1.00 & $0.97-1.03$ & 1.03 & $0.99-1.06$ \\
\hline Sex $=$ Male (ref. female) & 0.93 & $0.59-1.47$ & 0.86 & $0.52-1.42$ \\
\hline Subjective economic status $=$ Poor (ref. Better-off) & 1.51 & $0.89-2.54$ & 1.32 & $0.75-2.35$ \\
\hline \multicolumn{5}{|l|}{ Chronic disease = Having (ref. Not having) } \\
\hline Heart disease & 1.28 & $0.56-2.91$ & 0.88 & $0.36-2.13$ \\
\hline Diabetes & 1.38 & $0.77-2.46$ & 1.32 & $0.71-2.47$ \\
\hline Musculoskeletal disorder & 1.04 & $0.48-2.24$ & 0.83 & $0.36-1.91$ \\
\hline IADL = Dependent (ref. Independent) & $8.00^{* * *}$ & $4.90-13.07$ & $6.29^{* * *}$ & $3.47-11.39$ \\
\hline Depressive symptoms = Having (ref. Not having) & $2.10^{* *}$ & $1.30-3.41$ & $1.69^{*}$ & $1.00-2.85$ \\
\hline Living status = Living alone (ref = Living with someone) & 0.92 & $0.28-3.07$ & 1.41 & $0.39-5.09$ \\
\hline
\end{tabular}

Note: Ref: "Active," $P<0.05 ; * * P<0.01$; *** $P<0.001$, IADL Instrumental Activities of Daily living, Cl Confidence Interval

Interestingly, the comparison of the "Socially isolated" and "Less motivated" groups did not indicate a simple relationship in which one group's response probability was higher than that of the other in any domain of social relationships. This result meant that the two groups have different features in each domain, and that the social relationships between the two groups are qualitatively different, rather than simply expressing high and low. This finding may be useful in devising effective strategies for each pattern in public health practice.

We also investigated the differences in the factors associated with the higher probability of being allocated to the "Socially isolated" or "Less motivated" groups compared with the "Active" group. First, depressive symptoms were a common factor associated with the likelihood of being allocated to the "Socially isolated" or "Less motivated" groups. This result highlights the importance of improving depression interventions in both patterns of inactive social relationships. Once we consider these two groups as relatively inactive groups, this result may be consistent with previous studies that showed the association between poor social relationships and depressive symptoms. However, previous studies have reported a bidirectional relationship between social relationships and depression: Poor social relationships is associated with poor mental health outcomes [5-8], and depression may further reduce social involvement [33, 34]. The two inactive groups in the present study may be differently associated with depression both in terms of direction of causality and the associated effect sizes. Therefore, future longitudinal studies that clarify similarities and differences between the two groups and causality in more detail should be conducted to provide fruitful insights to improve the efficacy of interventions.

In addition, people who were dependent in their IADL functions were more likely to be allocated to the "Less motivated" or "Socially isolated" group. Furthermore, compared to the "Less motivated" group, the "Socially isolated" group showed significantly lower probability of dependency in their IADL function. While older adults experience functional decline and various aspects of loss with aging, social relationships are also said to reduce with time [35]. Another study also reported that social participation, such as poor participation in hobby clubs, senior citizen clubs, and volunteer groups was associated with future occurrence of IADL decline [36]. Considering that social frailty may precede physical frailty [37], it may be said that the "Less motivated" group is a group in which the beginnings of functional decline occur. Secondary prophylactic interventions may be essential in the "Less motivated" group to prevent further functional decline. 
Being male and living alone were associated with being allocated to the "Socially isolated" group. Our result is consistent with a previous study that reported the association of demographic factors such as sex, educational attainment, economic, and marital status with social isolation [38]. This study found that an understanding of the subject's background, such as cohabitation, might be desirable as a screening and intervention approach to the "Socially isolated" group. However, despite the reports about the impact on economic status $[38,39]$, it could not be confirmed using our model. One possible reason is that our study evaluated subjective economic status where participants were asked how they felt about their living economic status rather than an objective indicator. The gap between the subjective and actual situations could affect our results. Further, the effect of the other confounding factors also could be such that economic status may be associated with the transition to living alone [40] while living arrangement was associated with the "Socially isolated" group in this study. Although this study could not confirm the independent effect of subjective economic status, detailed further examination is necessary to consider complex background risk factors for developing interventions.

The limitations of this study should be noted. First, it was conducted in a limited area, which reduces the generalizability of the results. Additionally, the lack of power owing to the relatively small sample size may have affected the results. The small sample size of "Socially isolated" and "Less motivated" groups may reduce the power to detect the association between covariates and the likelihood of belonging to those groups. Further research should employ larger sample sizes to provide further and more robust evidence of the results. The current results may also be affected by a selection bias, given a possible association between the ISI subscales and actively participating for various events including our survey. Therefore, we cannot rule out the possibility that sizes of "Socially isolated" and "Less motivated" groups may be underestimated. In addition, people who did not participate in the survey might have belonged to another latent class apart from those identified in our analysis, which may be overcome by exploratory qualitative research such as interviews. Second, there may be other confounding factors like educational attainment that were not included in the data used in this study. Investigating possible confounding variables in future research is necessary. Third, we used data that was obtained before the COVID-19 pandemic. The pandemic has significantly changed people's way of life and social relationships. In the future, it would be useful to investigate the kind of changes that occurred in social relationships during and after the pandemic.
Based on these limitations, further studies are expected to be conducted to develop this research topic.

\section{Conclusion}

This study derived three social relationship patterns"Active," "Socially isolated," and "Less motivated" groups, and investigated differences in socio-demographic characteristics and mental and physical health status in those patterns. Inactive social relationships could be classified into two subtypes, and the characteristics of participants may differ by patterns of social relationships. Our work suggests the necessity of assessing individual's patterns of social relationships and creating strategies separately for each pattern, in the practice of public health: (1) intervention in mental health for both "Socially isolated" and "Less motivated" groups is essential as a comprehensive intervention policy for older adults, (2) in addition to mental health care, secondary prevention care for functions such as IADL may be necessary for "Less motivated" group, which may be declining social functioning, (3) since "Socially isolated" group tend to have demographic risks, such as living arrangement, understanding the background of the target is essential when intervention or screening is deemed necessary. Our finding is expected to contribute to the development of more effective interventions in the future.

\section{Abbreviations}

LCA: Latent class analysis; CEC study: Community empowerment and care for well-being and healthy longevity study; ISI: Index of Social Interaction; IADL: Instrumental activities and daily living; BIC: Bayesian Information Criterion; aBIC: Adjusted Bayesian Information Criterion; AIC: Akaike Information Criterion; CAIC: Consistent Akaike Information Criterion.

\section{Supplementary Information}

The online version contains supplementary material available at https://doi. org/10.1186/s12877-022-02748-7.

Additional file 1: Supplementary Table 1. Descriptive statistics of ISI scores.

Additional file 2: Supplementary Table 2. Correlation matrix for the five ISI subscales.

Additional file 3: Supplementary Table 3. The number of missing data among three latent classes.

Additional file 4: Supplementary Table 4. Multinomial logistic regression analysis for class memberships of social relationships compared to "Less motivated" group.

\section{Acknowledgments}

We are deeply grateful to Mr. Takayama (former principal investigator), Mr. Kuno (Mayor of Tobishima), Mr. Hattori (former Deputy Mayor of Tobishima), and all the study participants and staff.

\section{Authors' contributions}

KW contributed to the conception, design, analysis, drafting and revision of this paper. TS and MOM contributed to interpretation, drafting and revision of this paper. YS, ET, TW, ET, RO, and SI contributed to data collection. TA is 
principal investigator of the original data. All authors read and approved the final manuscript.

\section{Funding}

This work was sponsored by the municipality government of the target area and supported by JSPS KAKENHI Grant Numbers (21 K18449, 18KT0035, 19H01138, 20H05022, 20H05574); Grant-in-Aid for JSPS Fellows (21 J01494).

\section{Availability of data and materials}

The datasets are available from the corresponding author on reasonable request and if permission from the municipality of study area is granted.

\section{Declarations}

\section{Ethics approval and consent to participate}

The CEC study was approved by the ethics committee of the University of Tsukuba (1331-2) and Morinomiya University of Medical Sciences (2018-054). Written informed consent was waived according to the Ethical Guidelines for Medical and Health Research Involving Human Subjects in Japan because the analysis used anonymous data and participants reserved the opportunity to opt out from the study. All procedures were conducted in accordance with the ethical principles for medical research involving human subjects detailed in the Declaration of Helsinki.

\section{Consent for publication}

Not applicable.

\section{Competing interests}

The original project was sponsored by the municipality of the target area.

\begin{abstract}
Author details
${ }^{1}$ Japan Society for the Promotion of Science (JSPS), Kojimachi, Chiyoda-ku, Tokyo 102-0083, Japan. ${ }^{2}$ RIKEN Center for Advanced Intelligence Project, Nihonbashi, Tokyo 103-0027, Japan. ${ }^{3}$ Morinomiya University of Medical Sciences, Suminoe-ku, Osaka 559-8611, Japan. ${ }^{4}$ Musashino University, Ariake, Koto-ku, Tokyo 135-8181, Japan. ${ }^{5}$ College of Nursing and Nutrition, Shukutoku University, Nitona-cho, Chiba 260-8703, Japan. ${ }^{6}$ Faculty of Nursing and Medical Care, Keio University, Shinanomachi, Tokyo 160-0016, Japan. ${ }^{7}$ Department of Public Welfare, Tobishima, Aichi 490-1434, Japan. ${ }^{8}$ Faculty of Medicine, University of Tsukuba, 1-1-1 Tennodai, Tsukuba, Ibaraki 305-8575, Japan.
\end{abstract}

Received: 6 August 2021 Accepted: 23 December 2021

Published online: 25 January 2022

\section{References}

1. Krause N. Longitudinal study of social support and meaning in life. Psychol Aging. 2007;22(3):456-69.

2. Fowler JH, Christakis NA. Dynamic spread of happiness in a large social network: longitudinal analysis over 20 years in the Framingham heart study. BMJ. 2008;337:a2338.

3. Conner KA, Powers EA, Bultena GL. Social interaction and life satisfaction: an empirical assessment of late-life patterns. J Gerontol. 1979;34(1):116-21.

4. Huxhold O, Miche M, Schüz B. Benefits of having friends in older ages: differential effects of informal social activities on well-being in middle-aged and older adults. J Gerontol B Psychol Sci Soc Sci. 2014;69(3):366-75.

5. Teo AR, Choi HJ, Valenstein M. Social relationships and depression: ten-year follow-up from a nationally representative study. PLoS One. 2013;8(4):1-8

6. Santini Zl, Fiori KL, Feeney J, Tyrovolas S, Haro JM, Koyanagi A. Social relationships, loneliness, and mental health among older men and women in Ireland: a prospective community-based study. J Affect Disord. 2016;204:59-69.

7. Santini ZI, Koyanagi A, Tyrovolas S, Mason C, Haro JM. The association between social relationships and depression: a systematic review. J Affect Disord. 2015:175:53-65.

8. Cruwys T, Dingle GA, Haslam C, Haslam SA, Jetten J, Morton TA. Social group memberships protect against future depression, alleviate depression symptoms and prevent depression relapse. Soc Sci Med. 2013;98:179-86.

9. Berkman LF, Syme SL. Social networks, host resistance, and mortality: a nine-year follow-up study of Alameda County residents. Am J Epidemiol. 1979;109:186-204.

10. Holt-Lunstad J, Smith TB, Layton JB. Social relationships and mortality risk: a meta-analytic review. PLoS Med. 2010;7(7):e1000316.

11. Laugesen K, Baggesen LM, Schmidt SAJ, Glymour MM, Lasgaard M, Milstein A, et al. Social isolation and all-cause mortality: a population-based cohort study in Denmark. Sci Rep. 2018;8(1):4731.

12. Iwasaki M, Otani T, Sunaga R, Miyazaki H, Xiao L, Wang N, et al. Social networks and mortality based on the Komo-Ise cohort study in Japan. Int J Epidemiol. 2002;31:1208-18.

13. Ikeda A, Kawachi I, Iso H, Iwasaki M, Inoue M, Tsugane S. Social support and cancer incidence and mortality: the JPHC study cohort II. Cancer Causes Control. 2013;24:847-60.

14. Seeman TE, Bruce ML, McAvay GJ. Social network characteristics and onset of ADL disability: MacArthur studies of successful aging. J Gerontol B Psychol Sci Soc Sci. 1996;51(4):191-200.

15. Mendes de Leon CF, Glass TA, Beckett LA, Seeman TE, Evans DA, Berkman LF. Social networks and disability transitions across eight intervals of yearly data in the New Haven EPESE. J Gerontol B Psychol Sci Soc Sci. 1999;54(3):162-72.

16. Fratiglioni L, Wang HX, Ericsson K, Maytan M, Winblad B. Influence of social network on occurrence of dementia: a community-based longitudinal study. Lancet. 2000;355(9212):1315-9.

17. Kuiper JS, Zuidersma M, Oude Voshaar RC, Zuidema SU, van den Heuvel ER, Stolk RP, et al. Social relationships and risk of dementia: a systematic review and meta-analysis of longitudinal cohort studies. Ageing Res Rev. 2015;22:39-57.

18. Cohen S. Social relationships and health. Am Psychol. 2004;59(8):676-84.

19. Fakoya OA, McCorry NK, Donnelly M. Loneliness and social isolation interventions for older adults: a scoping review of reviews. BMC Public Health. 2020;20(1):129.

20. Cattan M, White M, Bond J, Learmouth A. Preventing social isolation and loneliness among older people: a systematic review of health promotion interventions. Ageing Soc. 2005;25(1):41-67.

21. Hikichi H, Kondo N, Kondo K, Aida J, Takeda T, Kawachi I. Effect of a community intervention programme promoting social interactions on functional disability prevention for older adults: propensity score matching and instrumental variable analyses, JAGES Taketoyo study. J Epidemiol Community Health. 2015;69(9):905-10.

22. Hikichi H, Kondo K, Takeda T, Kawachi I. Social interaction and cognitive decline: results of a 7-year community intervention. Alzheimers Dement. 2017;3(1):23-32.

23. Baker R, Camosso-Stefinovic J, Gillies C, Shaw EJ, Cheater F, Flottorp S, et al. Tailored interventions to overcome identified barriers to change: effects on professional practice and health care outcomes. Cochrane Database Syst Rev. 2010;3:CD005470.

24. Dawson-Townsend K. Social participation patterns and their associations with health and well-being for older adults. SSM Popul Health. 2019;8:100424.

25. Ukawa S, Tamakoshi A, Okada Y, Ito YM, Taniguchi R, Tani Y, et al. Social participation patterns and the incidence of functional disability: the Japan Gerontological evaluation study. Geriatr Gerontol Int. 2020;20(8):765-72.

26. Anme T. Evaluation of environmental stimulation and its relation to physical deterioration in the elderly after 3 years - a health - social longitudinal study. Nihon Koshu Eisei Zasshi. 1997:44(3):159-66.

27. Koyano W, Shibata H, Nakazato K, Haga H, Suyama Y. Measurement of competence: reliability and validity of the TMIG index of competence. Arch Gerontol Geriatr. 1991;13(2):103-16.

28. Ministry of Health, Labour and Welfare. The concept of a complete survey of needs in the sphere of daily life. Tokyo: Ministry of Health, Labour and Welfare; 2013. http://www.mhlw.go.jp/file/05-Shingikai-12301000-Rouke nkyoku-Soumuka/0000138620.pdf. Accessed 30 Apr 2021. [In Japanese]

29. Whooley MA, Avins AL, Miranda J, Browner WS. Case-finding instruments for depression. Two questions are as good as many. J Gen Intern Med. 1997;12(7):439-45. 
30. Berlin KS, Williams NA, Parra GR. An introduction to latent variable mixture modeling (part 1): overview and cross-sectional latent class and latent profile analyses. J Pediatr Psychol. 2014;39(2):174-87.

31. Amano T, Morrow-Howell N, Park S. Patterns of social engagement among older adults with mild cognitive impairment. J Gerontol B Psychol Sci Soc Sci. 2020;75(7):1361-71.

32. van Hees SGM, van den Borne BHP, Menting J, Sattoe JNT. Patterns of social participation among older adults with disabilities and the relationship with well-being: a latent class analysis. Arch Gerontol Geriatr. 2020;86:103933

33. Luo Y, Hawkley LC, Waite LJ, Cacioppo JT. Loneliness, health, and mortality in old age: a national longitudinal study. Soc Sci Med. 2012;74(6):907-14.

34. Elmer T, Stadtfeld C. Depressive symptoms are associated with social isolation in face-to-face interaction networks. Sci Rep. 2020;10:1444

35. Charles ST, Carstensen LL. Social and emotional aging. Annu Rev Psychol. 2010;61:383-409.

36. Tomioka K, Kurumatani N, Hosoi H. Association between social participation and 3-year change in instrumental activities of daily living in community-dwelling elderly adults. J Am Geriatr Soc. 2017;65(1):107-13.

37. Makizako H, Shimada H, Doi T, Tsutsumimoto K, Hotta R, Nakakubo S, et al. Social frailty leads to the development of physical frailty among physically non-frail adults: a four-year follow-up longitudinal cohort study. Int J Environ Res Public Health. 2018;15(3):490.

38. Cudjoe TKM, Roth DL, Szanton SL, Wolff JL, Boyd CM, Thorpe RJ. The epidemiology of social isolation: National Health and aging trends study. J Gerontol B Psychol Sci Soc Sci. 2020;75(1):107-13.

39. Stewart MJ, Makwarimba E, Reutter LI, Veenstra G, Raphael D, Love R. Poverty, sense of belonging and experiences of social isolation. J Poverty. 2009;13(2):173-95.

40. Martikainen P, Nihtilä E, Moustgaard H. The effects of socioeconomic status and health on transitions in living arrangements and mortality: a longitudinal analysis of elderly Finnish men and women from 1997 to 2002. J Gerontol B Psychol Sci Soc Sci. 2008;63(2):99-109.

\section{Publisher's Note}

Springer Nature remains neutral with regard to jurisdictional claims in published maps and institutional affiliations.

Ready to submit your research? Choose BMC and benefit from:

- fast, convenient online submission

- thorough peer review by experienced researchers in your field

- rapid publication on acceptance

- support for research data, including large and complex data types

- gold Open Access which fosters wider collaboration and increased citations

- maximum visibility for your research: over $100 \mathrm{M}$ website views per year

At BMC, research is always in progress.

Learn more biomedcentral.com/submissions 